Supporting Information 


\section{Dendrimer-Ni-Based Material: Toward an Efficient Ni-Fe Layered Double Hydroxide for Oxygen-Evolution Reaction}

Mahya Salmanion ${ }^{\mathrm{a}}$ and Mohammad Mahdi Najafpour ${ }^{\mathrm{a}-\mathrm{c}^{*}}$

aDepartment of Chemistry, Institute for Advanced Studies in Basic Sciences (IASBS), Zanjan, 45137-

66731, Iran

${ }^{b}$ Center of Climate Change and Global Warming, Institute for Advanced Studies in Basic Sciences (IASBS),

Zanjan, 45137-66731, Iran

'Research Center for Basic Sciences \& Modern Technologies (RBST), Institute for Advanced Studies in

Basic Sciences (IASBS), Zanjan 45137-66731, Iran

*Corresponding author: Tel: (+98) 243315 3201, E-mail: mmnajafpour@iasbs.ac.ir (MMN). 


\section{Table of contents}

\begin{tabular}{|c|c|}
\hline Title & Page \\
\hline Experimental Section & S4-S5 \\
\hline Scheme S1 (Scheme of the electrochemical experimental setup) & S6 \\
\hline Figure S1 (SEM images of a bare FTO electrode) & S7 \\
\hline $\begin{array}{l}\text { Figure S2 (Photograph of precatalyst and SEM images of the attached precatalyst on the } \\
\text { surface of a bare FTO) }\end{array}$ & S8 \\
\hline $\begin{array}{l}\text { Figure S3 (SEM-EDX mapping analysis and EDX spectrum of the attached precatalyst on the } \\
\text { surface of a bare FTO in the absence of potential) }\end{array}$ & S9 \\
\hline Figure S4 (SEM images of compound 1) & S10 \\
\hline Figure S5 (SEM-EDX mapping analysis and EDX spectrum of compound 1) & S11 \\
\hline $\begin{array}{l}\text { Figure S6 (AFM image of the precatalyst attached on the surface of a bare FTO in the absence } \\
\text { of potential) }\end{array}$ & S12 \\
\hline Figure S7 (AFM image of compound 1) & S13 \\
\hline Figure S8 ((HR)TEM images of precatalyst at different magnifications) & S14 \\
\hline Figure S9 (HRTEM images of compound 1) & S15 \\
\hline $\begin{array}{l}\text { Figure S10 (High-resolution XPS at oxygen region for the precatalyst attached to a bare FTO in } \\
\text { the absence of potential and after } 50 \text { consecutive CVs) }\end{array}$ & S16 \\
\hline Figure S11 (Chronoamperometry, CV and LSV of compound 1 using GC electrode) & S17 \\
\hline $\begin{array}{l}\text { Figure S12 (Four consecutive CVs in a } \mathrm{KOH} \text { solution }(1.0 \mathrm{M} \text { ) for the attached precatalyst on the } \\
\text { surface of a bare GC in the absence of } \mathrm{Fe}(\mathrm{III}) . \text { ) }\end{array}$ & S18 \\
\hline Figure S13 (Chronoamperometry, CV and LSV of compound 1 using Au electrode) & S19 \\
\hline Figure S14 (Chronoamperometry, CV and LSV of compound 1 using Pt electrode) & S20 \\
\hline Figure S15 (Chronoamperometry, CV and LSV of compound 1 using Ni foam electrode) & $\mathrm{S} 21$ \\
\hline Table S1 (Comparison of some heterogeneous water-oxidizing catalysts) & S22 \\
\hline References & S23 and S24 \\
\hline
\end{tabular}




\section{Materials}

All reagents and solvents were purchased from the commercial sources and used without further purifications. $\mathrm{Fe}\left(\mathrm{ClO}_{4}\right)_{3} \cdot 6 \mathrm{H}_{2} \mathrm{O}, \mathrm{Ni}\left(\mathrm{NO}_{3}\right)_{2} \cdot 6 \mathrm{H}_{2} \mathrm{O}(99.999 \%$ trace metals basis), FTO, Nafion (117 solution, 5 $\%)$, and PAMAM dendrimer $(200 \mathrm{~mL}$, ethylenediamine core, generation 3.5 solution sodium carboxylate surface groups (10 wt. \% in methanol)) were purchased from Sigma-Aldrich Company. KOH pellets (Fe (Iron) $\leq 0.0005 \%$ ) was purchased from Merck Company.

Precatalyst: $\mathrm{Ni}\left(\mathrm{NO}_{3}\right)_{2} \cdot 6 \mathrm{H}_{2} \mathrm{O}(500 \mathrm{mg}(1.70 \mathrm{mmol}), 99.999 \%$ trace metals basis) was dissolved in water (10 $\mathrm{mL})$. PAMAM dendrimer $(20 \mu \mathrm{L}$, ethylenediamine core, generation 3.5 solution sodium carboxylate surface groups ( $10 \mathrm{wt}$. \% in methanol)) was added to the solution and was under stirrer for 10 hours. The solid (light green) was centrifuged and washed with water three times $(5 \mathrm{~mL})$ and dried in air at $40{ }^{\circ} \mathrm{C}$.

Nafion preparation: Nafion $(5 \mu \mathrm{L})$, 2-Propanol $(100 \mu \mathrm{L})$ and $\mathrm{H}_{2} \mathrm{O}(100 \mu \mathrm{L})$ mixed, then, the solution was sonicated for 5 minutes and then the mixture was used.

Electrode preparation: $50 \mu \mathrm{L}$ of precatalyst $(0.1 \mathrm{mg} / \mathrm{mL})$ mixed with $5 \mu \mathrm{L}$ of Nafion, 2-Propanol $(100 \mu \mathrm{L})$, and $\mathrm{H}_{2} \mathrm{O}(100 \mu \mathrm{L})$. The solution sonicated for 5 minutes and then the mixture $(20 \mu \mathrm{L})$ was placed on the electrode surface. Then, the electrode was dried in air at $40{ }^{\circ} \mathrm{C}$ for 5 hours. Finally, the electrode was placed in electrochemistry setup and used for OER.

Compound 1: The Precatalyst under consecutive CVs $(1.16-1.66 \mathrm{~V}$ ) (scan rate: $10 \mathrm{mV} / \mathrm{s}$ ) or chronoamperometry at 1.66 was operated in the presence of $\mathrm{Fe}(\mathrm{III})\left(\mathrm{Fe}\left(\mathrm{ClO}_{4}\right)_{3} \cdot 6 \mathrm{H}_{2} \mathrm{O}\right.$, total concentration: $18 \mu \mathrm{M})$ in $\mathrm{KOH}(1.0 \mathrm{M})$. A solution of $\mathrm{Fe}\left(\mathrm{ClO}_{4}\right)_{3} \cdot 6 \mathrm{H}_{2} \mathrm{O}$ (Warning! perchlorate salts are hazardous because of the possibility of explosion; $0.21 \mathrm{mM}$ ) was added to the electrolyte using a micropipette; total concentration: $18 \mu \mathrm{M}$ ). Fe salt was added to the solution until a constant current density was observed.

\section{Characterizations}

Scanning electron microscopy (SEM) was carried out with LEO 1430VP, and high-resolution transmission electron microscopy (HRTEM) and TEM analyses were performed with Philips CM120 electron microscopy. EDX analysis/mapping was carried out with the scanning electron microscope CamScan 4DV (CamScan UK). X-ray photoelectron spectroscopy (XPS, K-ALPHA, Thermo Scientific) was used to analyze the surface of the sample. All spectra were collected using Al- $\mathrm{K}_{\alpha}$ radiation $(1486.6 \mathrm{eV})$, monochromatized by a twin crystal monochromator, yielding a focused X-ray spot at $3 \mathrm{~mA} \times 12 \mathrm{kV}$. The alpha hemispherical analyzer was operated in the constant energy mode with survey scan pass energies of $200 \mathrm{eV}$ to measure the whole energy band and $50 \mathrm{eV}$ in a narrow scan to selectively measure the particular elements. XPS data were analyzed with Avantage software. A smart background function was used to approximate the experimental backgrounds and, surface elemental composition was calculated from backgroundsubtracted peak areas. Charge compensation was achieved with the system flood gun that provides low energy electrons and low energy argon ions from a single source. The penetration depth is around $3 \mathrm{~nm}$. Electrochemical experiments were performed using an EmStat3+ from PalmSens (Netherlands) (Scheme S1). LSV and CV were performed from low to high potential. A three-electrode setup was used with an $\mathrm{Hg} / \mathrm{HgO}$, a Pt foil, and GC $\left(\left(0.0314 \mathrm{~cm}^{2}\right), \mathrm{FTO}\left(1.0 \mathrm{~cm}^{2}\right), \mathrm{Pt}\left(0.0314 \mathrm{~cm}^{2}\right)\right.$ or $\mathrm{Au}\left(0.0314 \mathrm{~cm}^{2}\right)$ as the reference, counter and working electrodes, respectively. To convert the measured potential to RHE, it is determined 
by cyclic voltammetry (CV) in the range of hydrogen evolution/oxidation at a Pt electrode in $\mathrm{H}_{2}$-saturated electrolyte, using a $\mathrm{H}_{2}$ generation, with the scan rate of $10 \mathrm{mV} / \mathrm{s}$ under stirrer at zero current.

The distance between two opposite sides of the foil electrode was measured by a digital caliper MarCal 16ER model (Mahr, Germany). The temperature was measured by Laserliner 082 (Germany). Oxygen was measured with an HQ40d portable dissolved oxygen-meter connected to an oxygen monitor with a digital readout at $25^{\circ} \mathrm{C}$. The measurement was first done for with air-saturated water to calibrate the oxygen meter. Raman spectra are collected from the electrode surface before and after consecutive CVs (range: 1.16-1.66 V, scan rate: $10 \mathrm{mV} / \mathrm{s}$ ). Raman spectra were collected by XploRA ONE ${ }^{\mathrm{TM}}$ Raman Microscope from Horiba Company using $532 \mathrm{~nm}$ laser. The devolution plots were calculated by Origin software using Gauss function. The Raman spectra were performed by the software "LabSpec 6 from" from Horiba Company. It has an auto-calibration software-ensures the data is always accurate. 


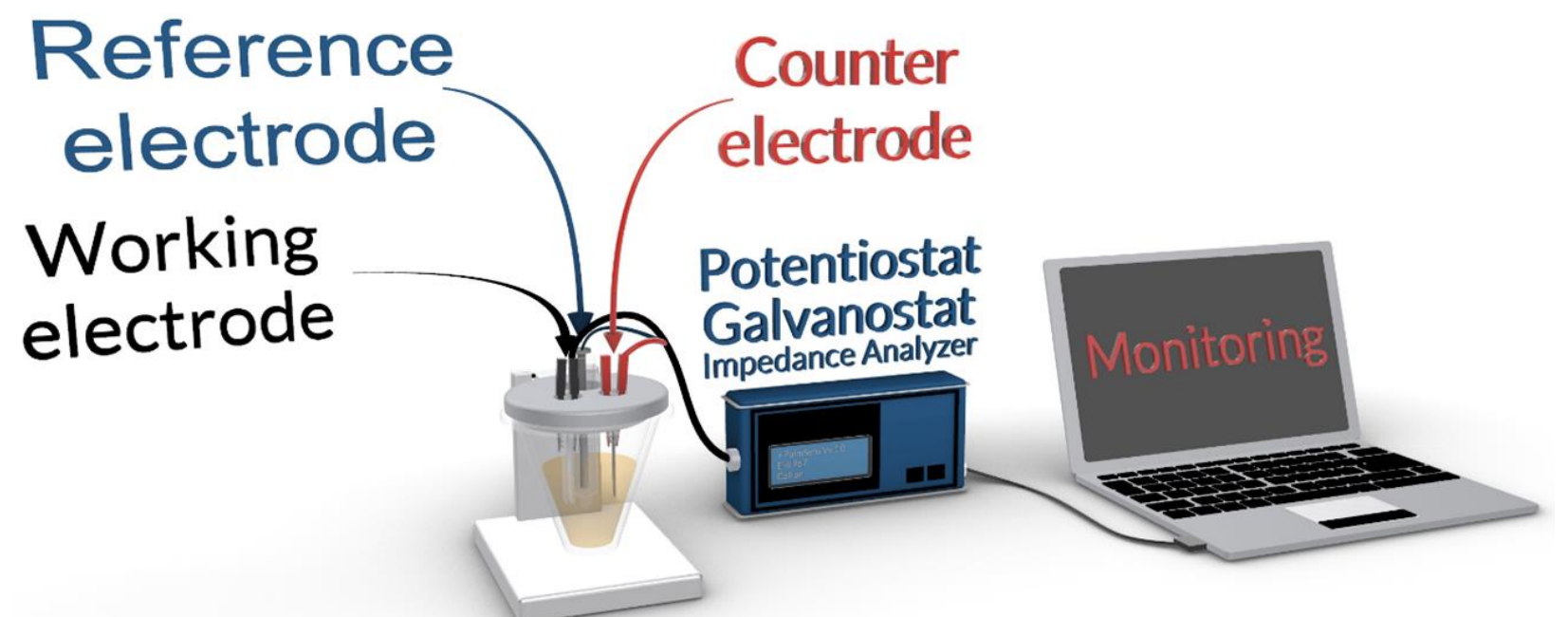

Scheme S1. The setup for the electrochemical experiment. A three-electrode setup was used with an $\mathrm{Hg} / \mathrm{HgO}$, a Pt foil, and GC (FTO, Pt, Au, or Ni foam) as the reference, counter and working electrodes, respectively. 


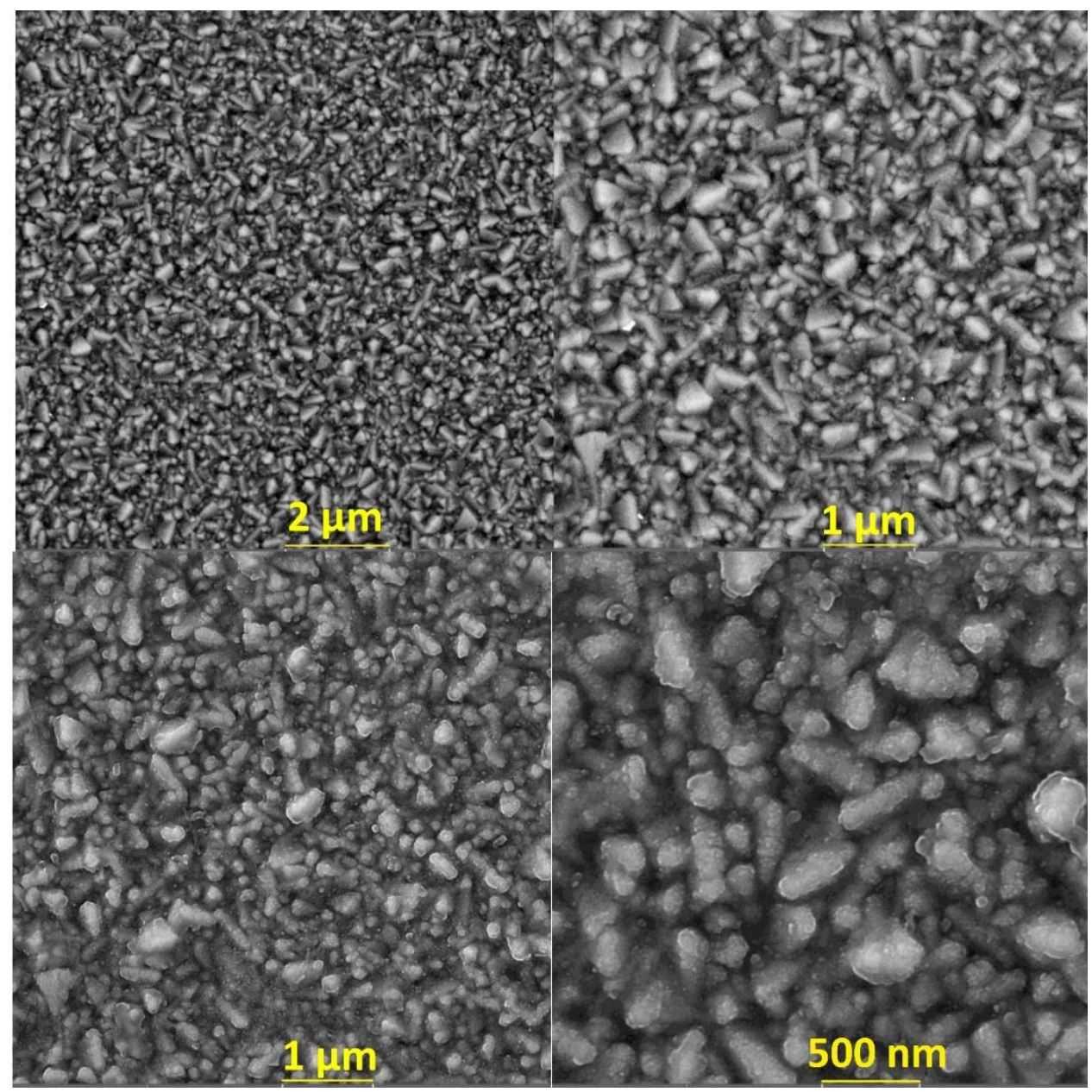

Figure S1 SEM images of a bare FTO electrode at different magnifications. 


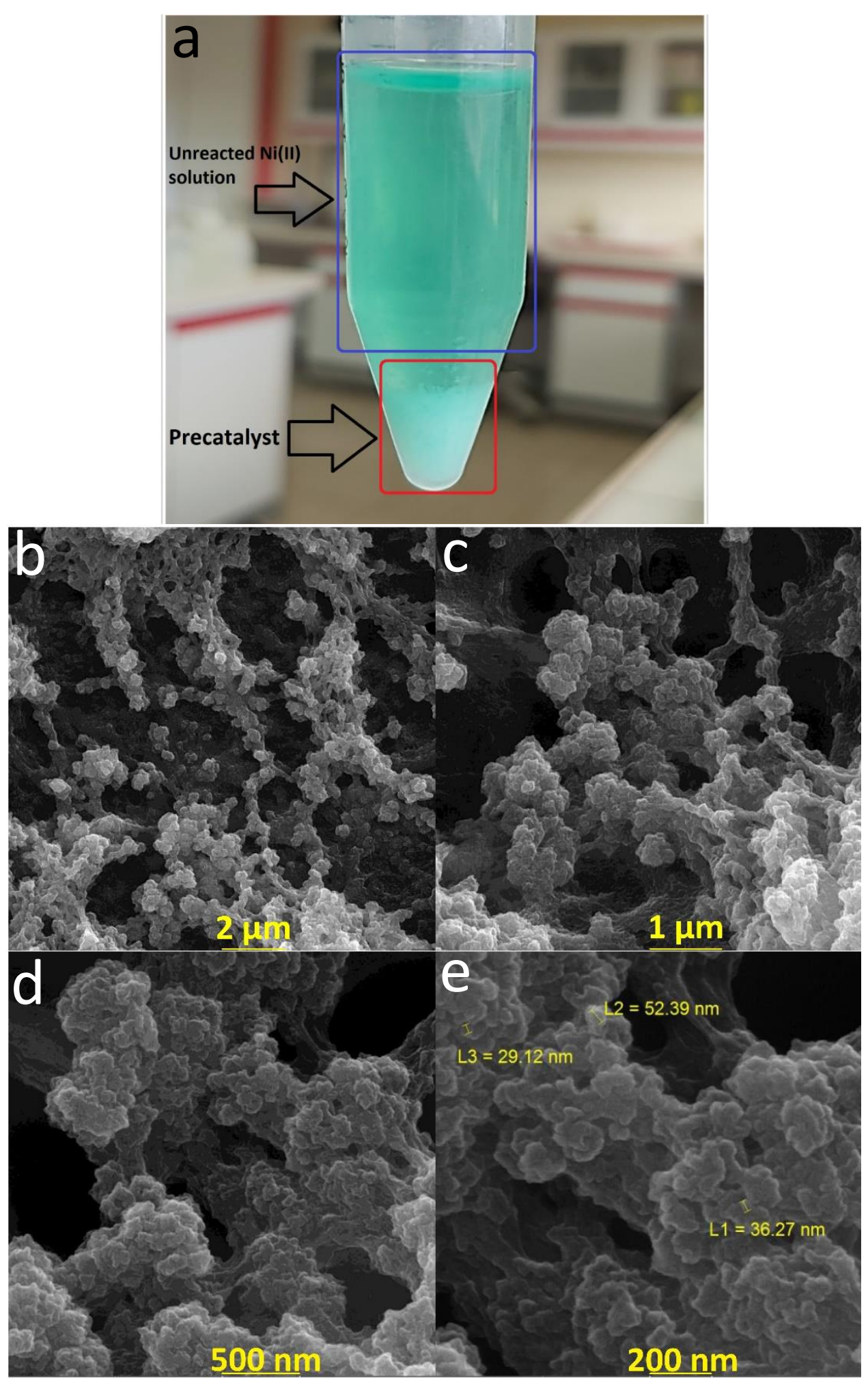

Figure S2 Photograph of synthesized precatalyst, the red rectangle shows a precatalyst as a light green solid after 10 hours of stirring ready to be centrifuge and wash with water. The top green solution (blue rectangle) is unreacted nickel nitrate solution (a). SEM images of the loaded precatalyst on the surface of a bare FTO in the absence of potential at different magnifications (b-e). 

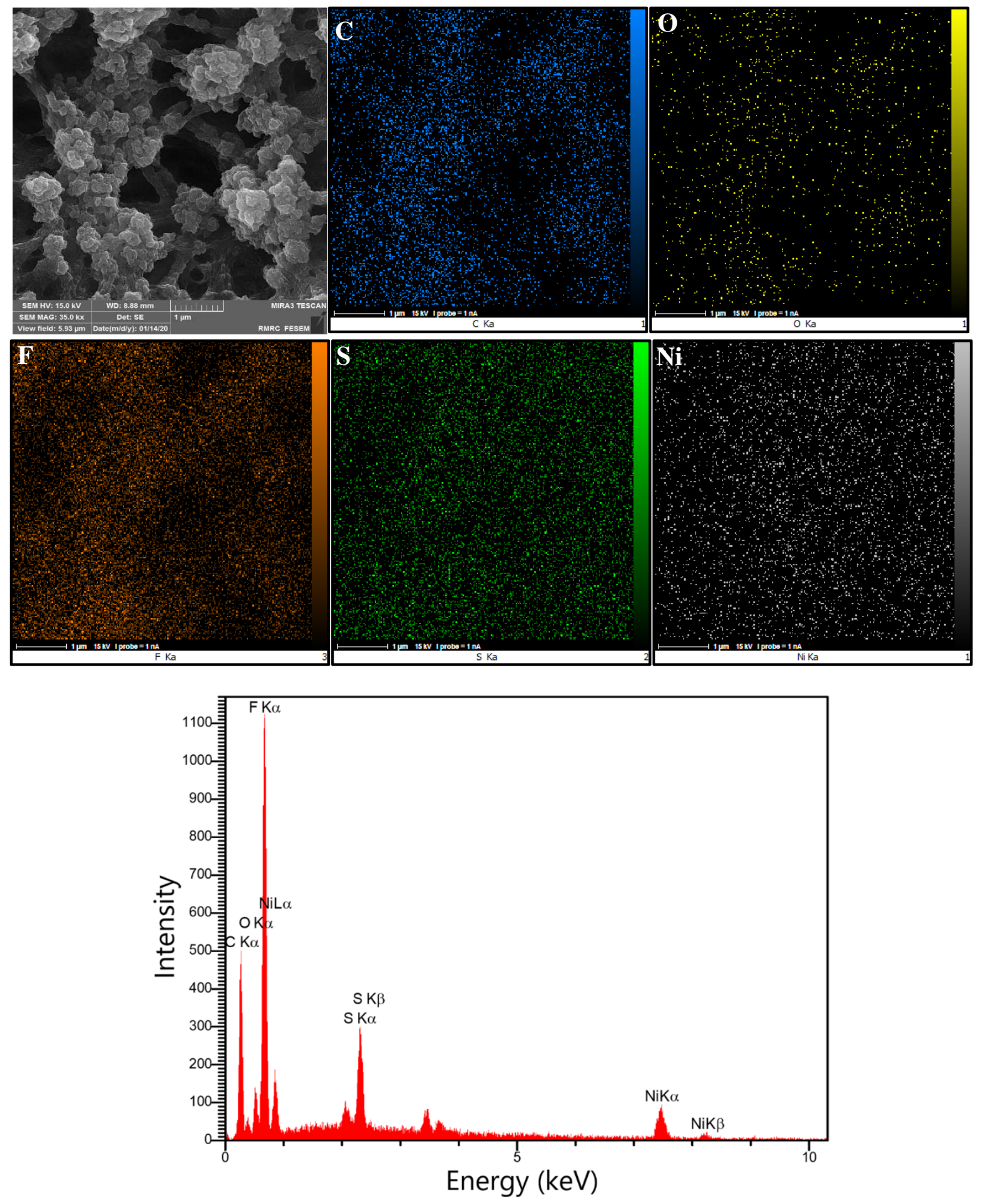

Figure S3 SEM-EDX mapping analysis and EDX spectrum of the loaded precatalyst on the surface of a bare FTO in the absence of potential. 

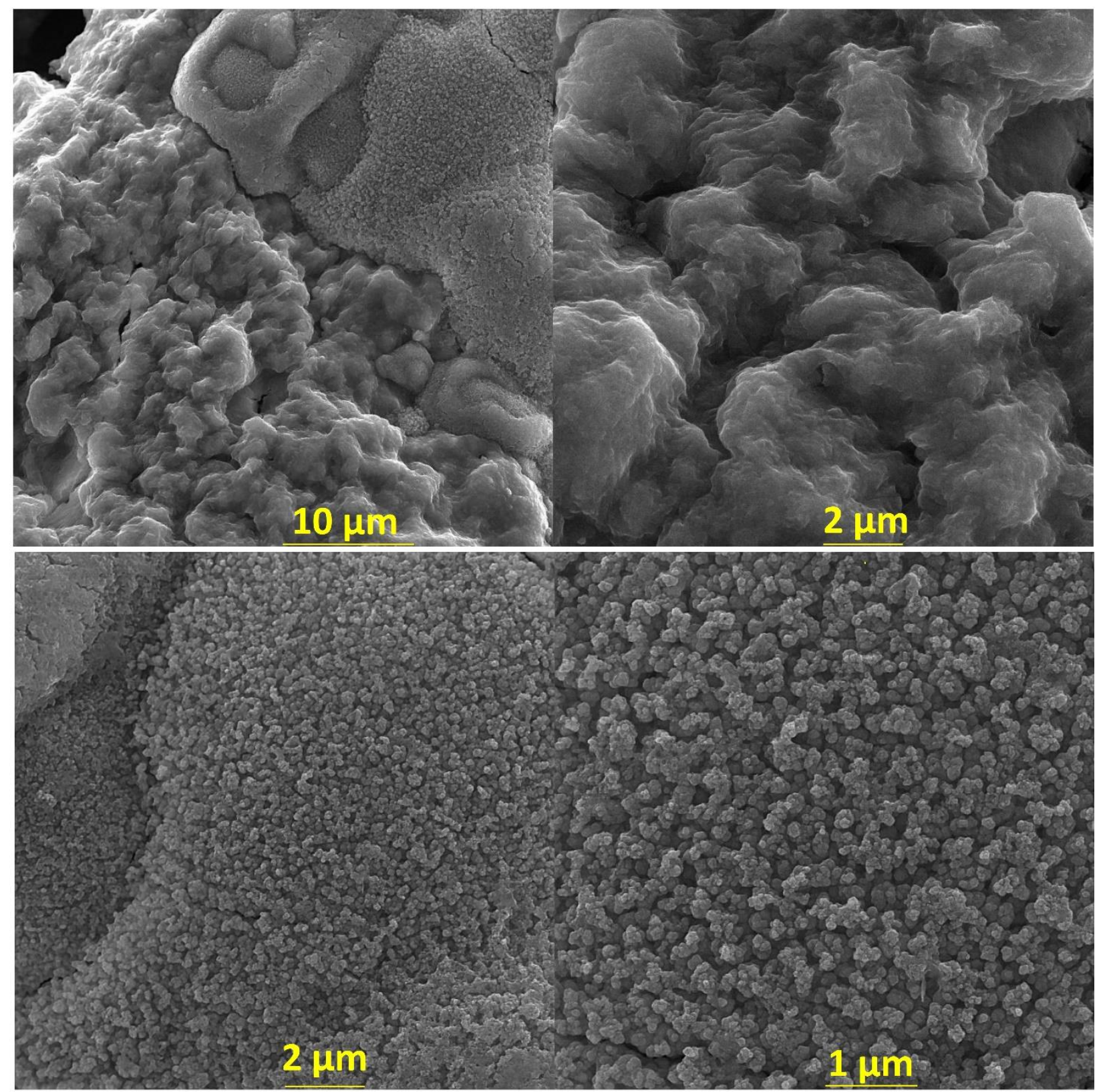

Figure S4 SEM images of compound 1 at different magnifications. For the details see Figure 3. 

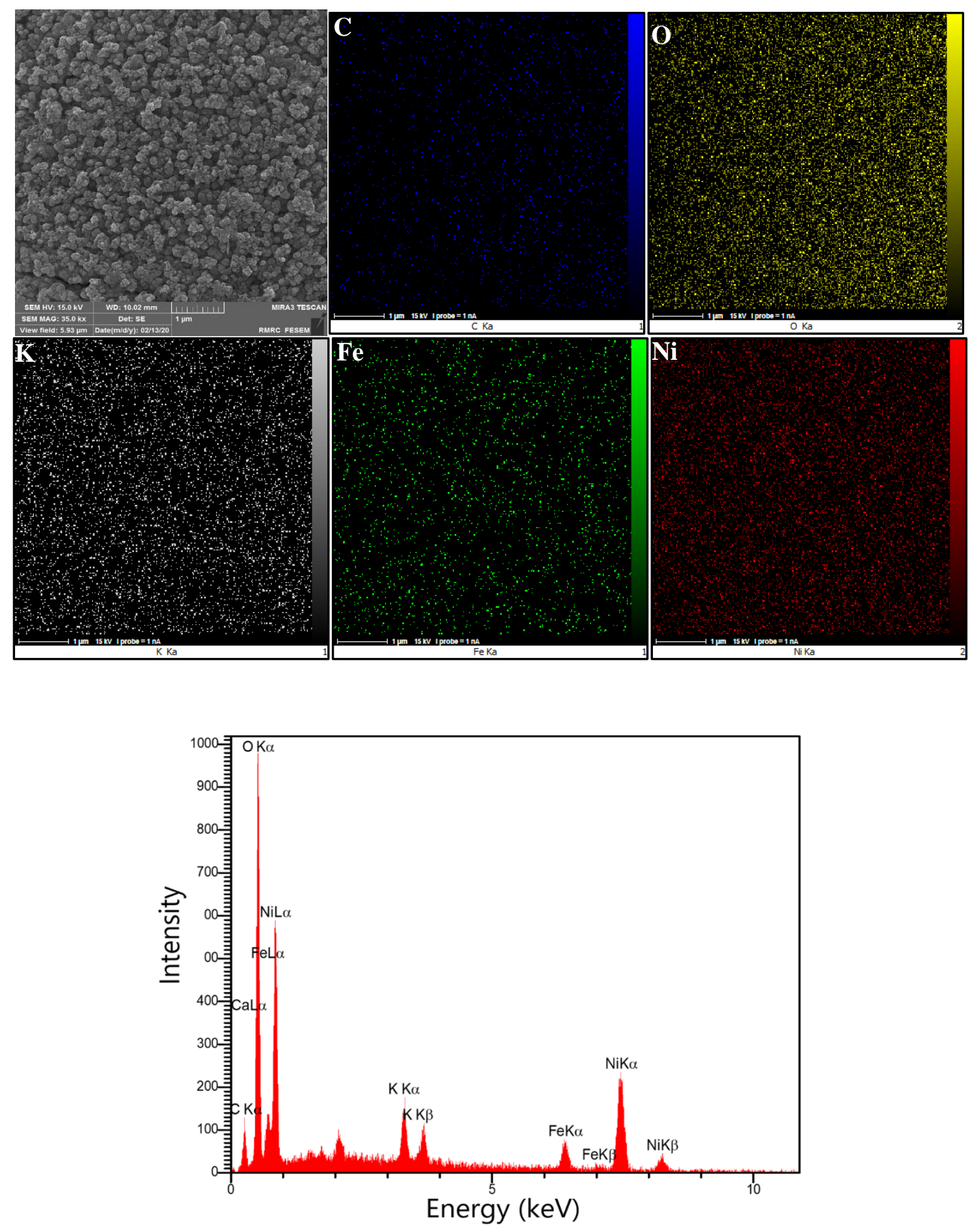

Figure S5 SEM-EDX mapping analysis and EDX spectrum of compound 1. For the details see Figure 3. 


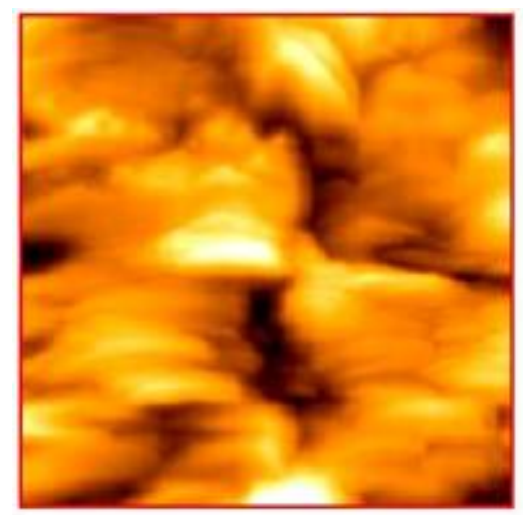

$(12,220) \times 2.34 \mu \mathrm{m}$ y. $42.97 \mathrm{~mm} \times 0.8706 \mathrm{~mm}$

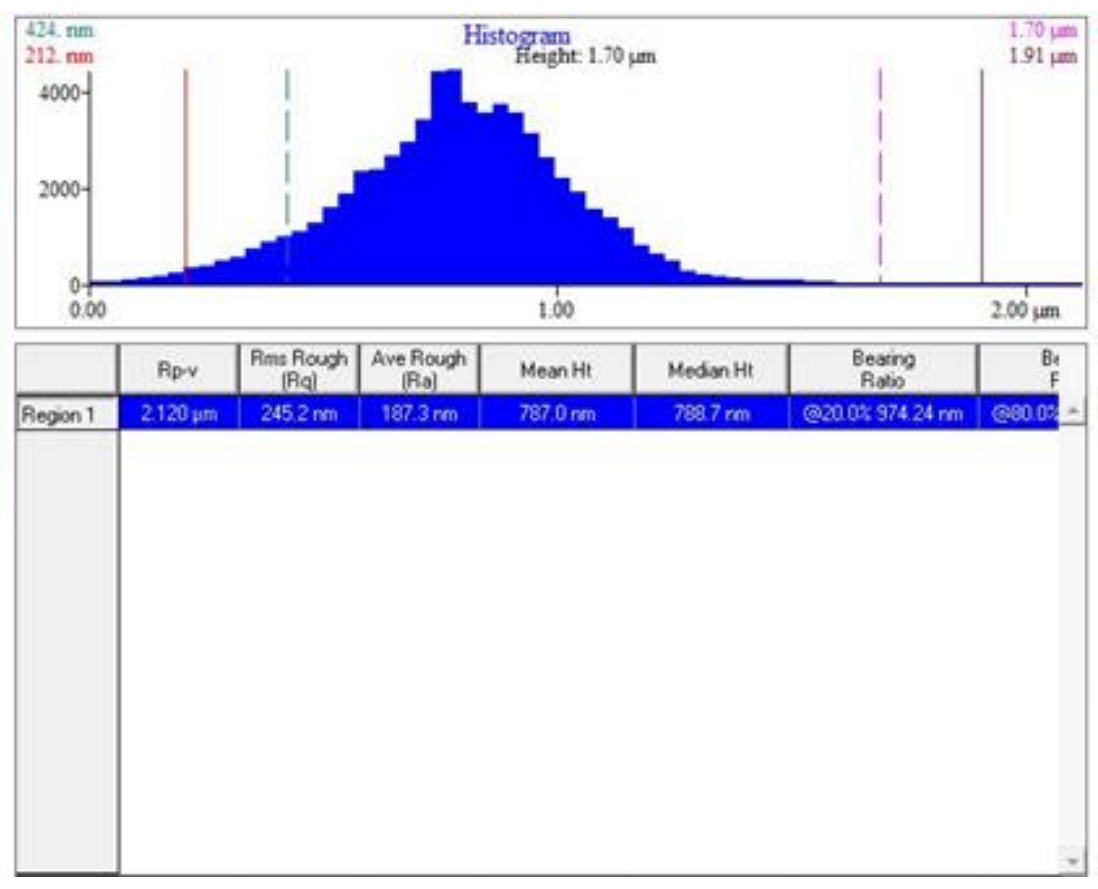

Figure S6 AFM image of the precatalyst loaded on the surface of a bare FTO in the absence of potential. For the details see Figure 4. 


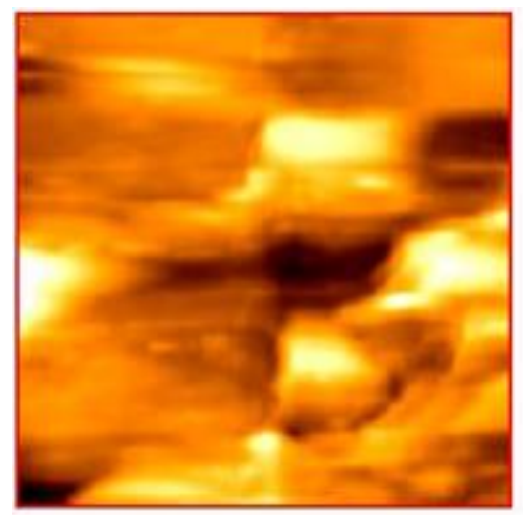

$(16,223) \times 3.13$ pen y: $43.55 \mu \mathrm{m} z: 0.8662 \mu$

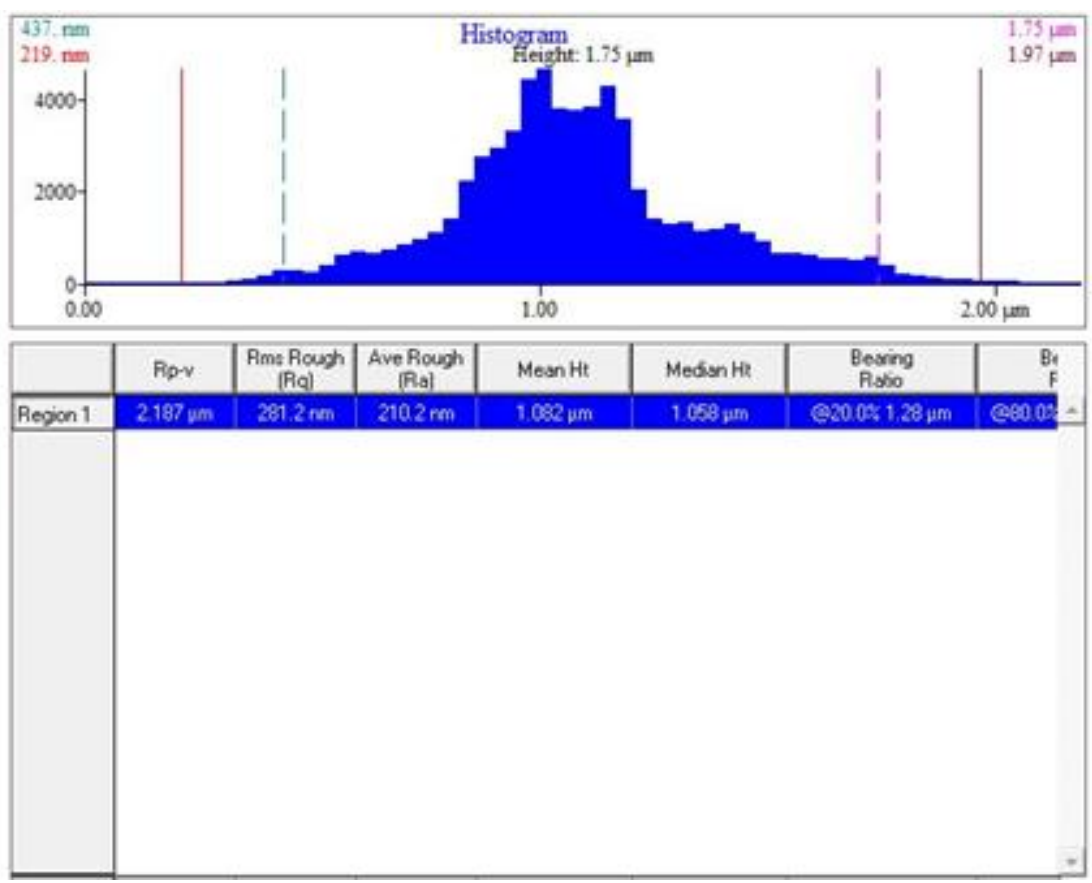

Figure S7 AFM image of compound 1. For the details see Figure 4. 


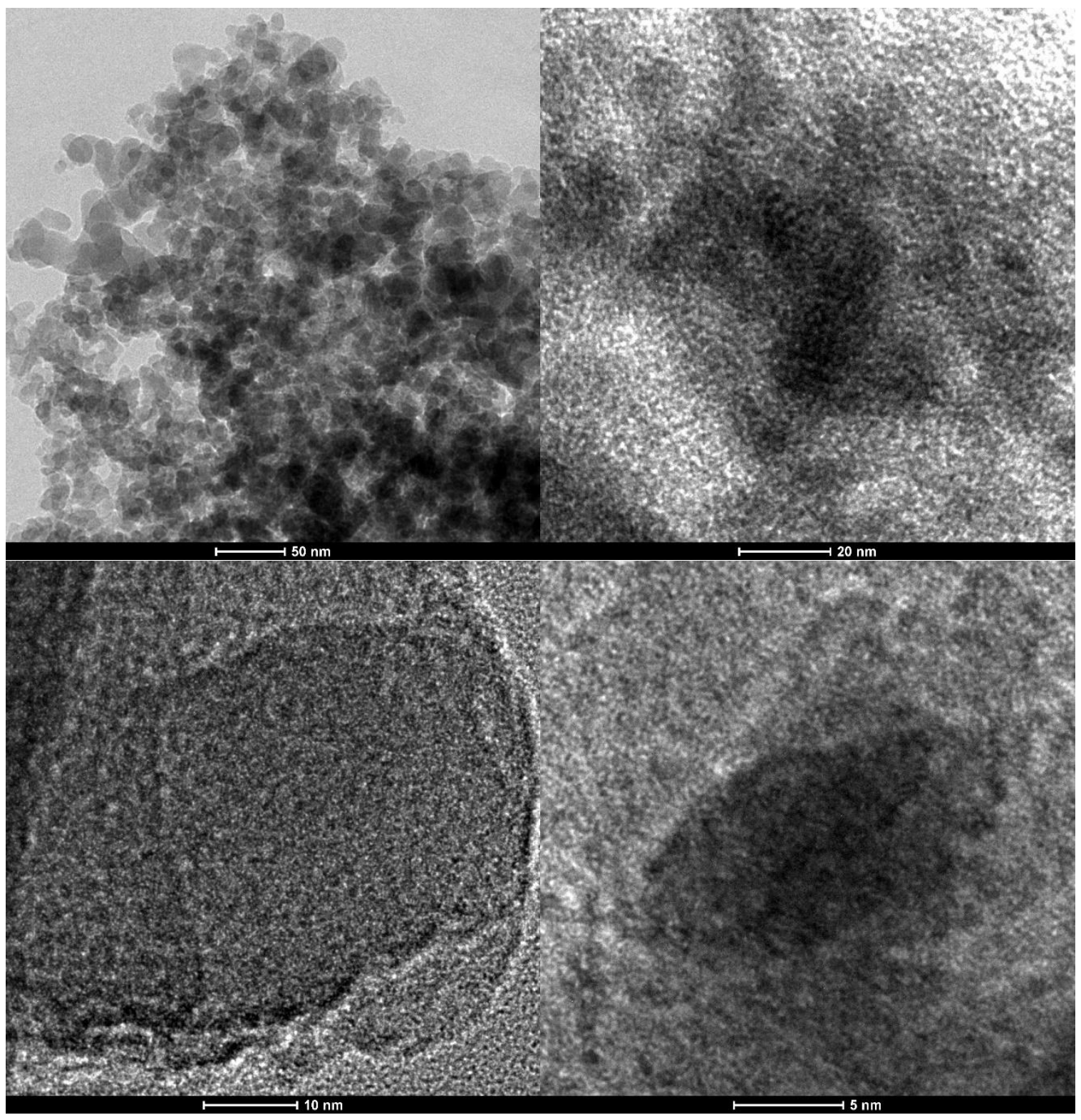

Figure S8 (HR)TEM images of precatalyst at different magnifications. 


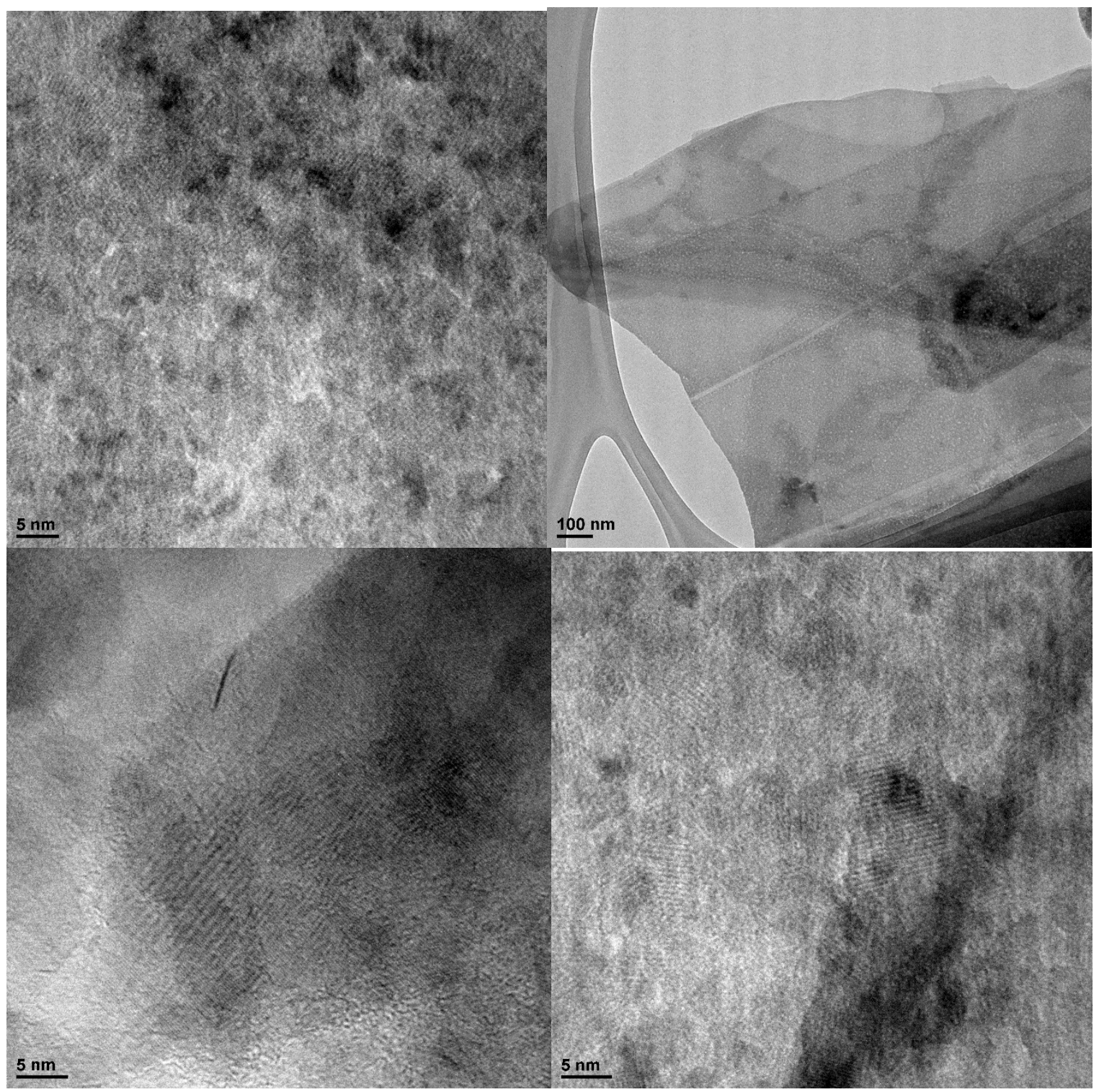

Figure S9 HRTEM images of compound 1 at different magnifications. For the details see Figure 5. 

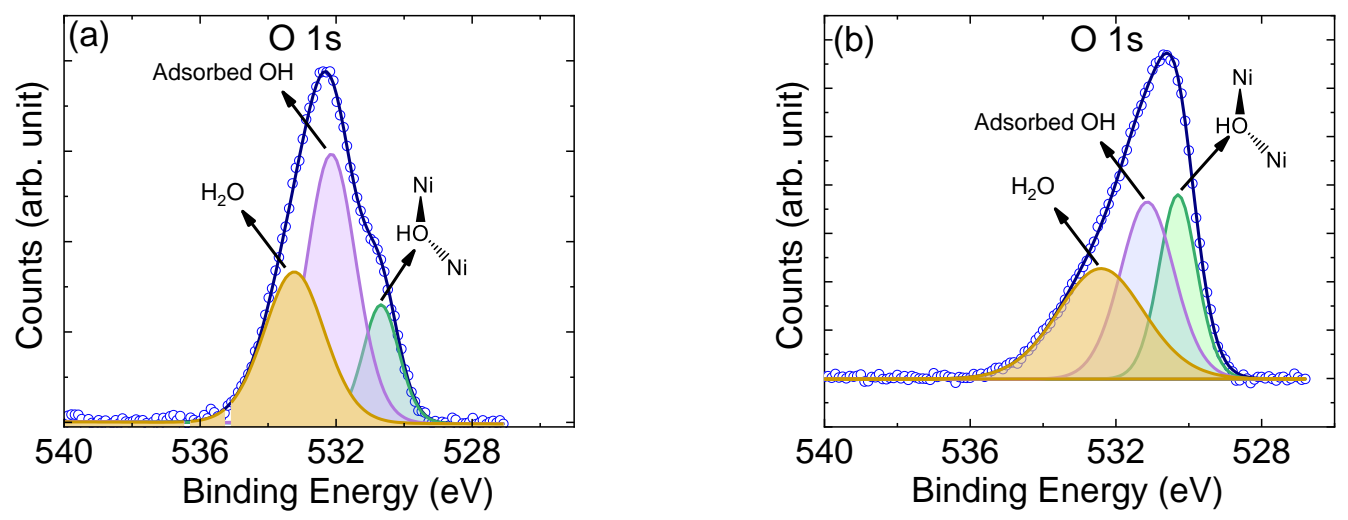

Figure S10 High-resolution XPS at oxygen region for the precatalyst loaded to a bare FTO in the absence of potential (a) and compound 1 (b). For the details see Figure 6. 

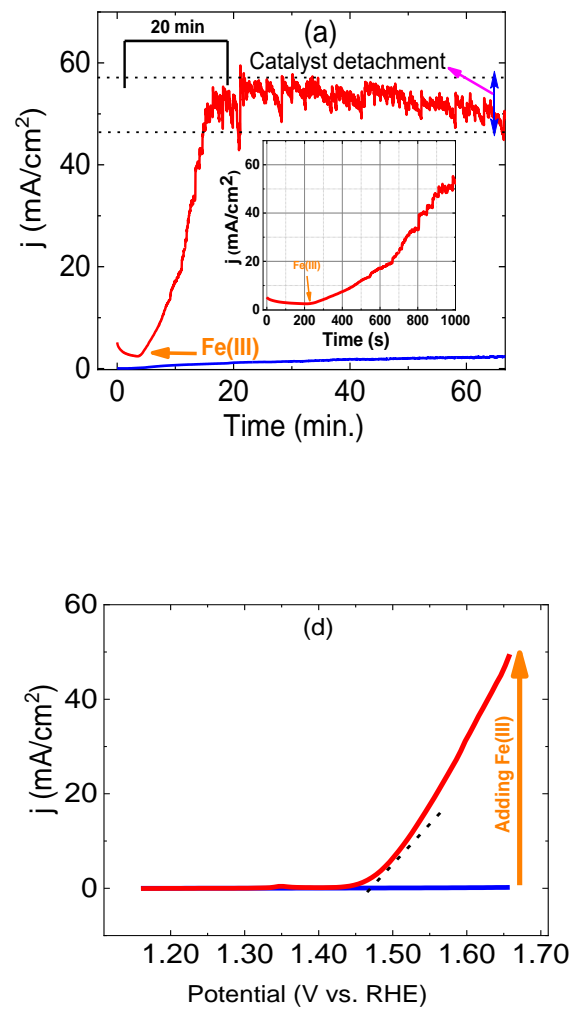
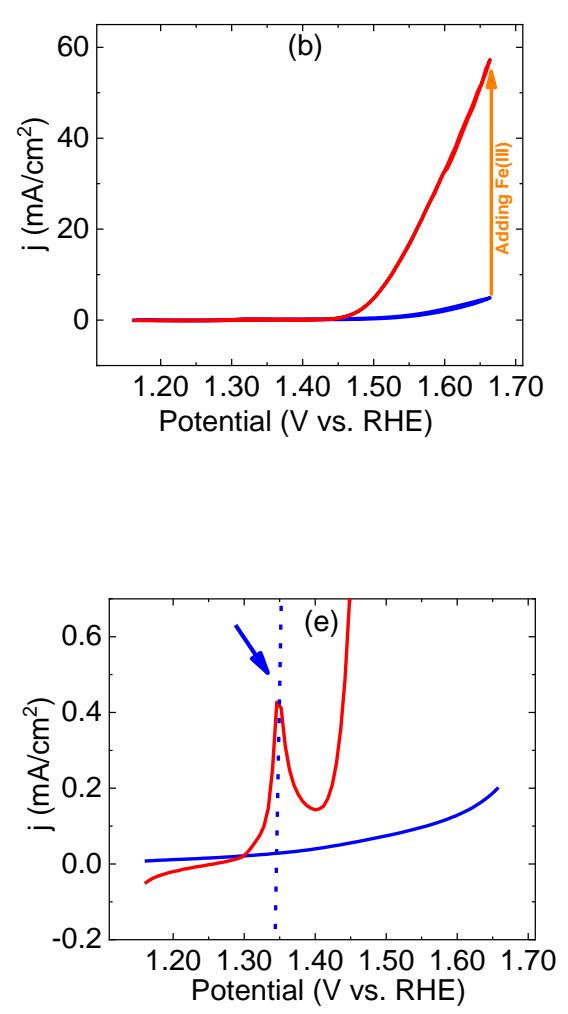
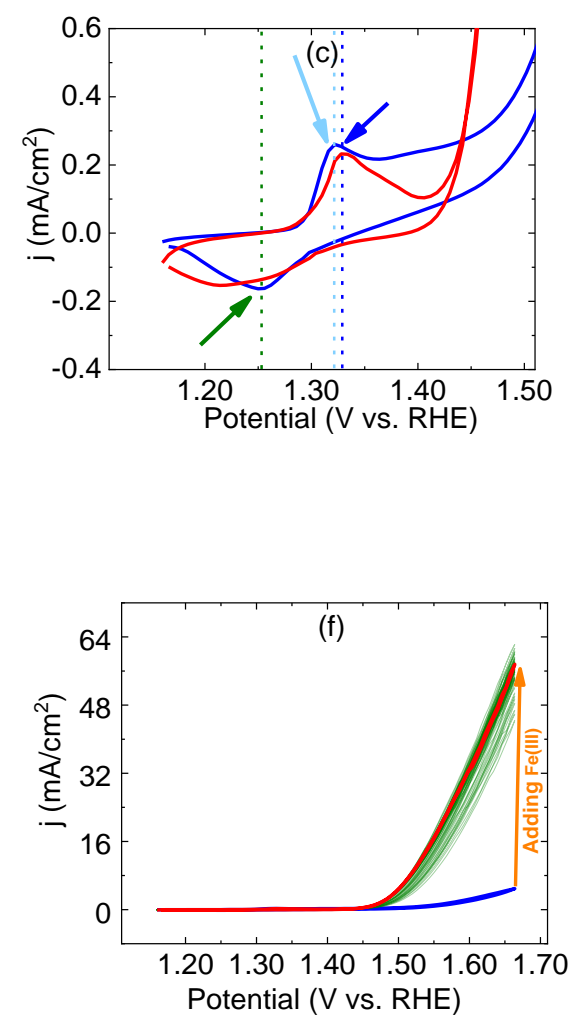
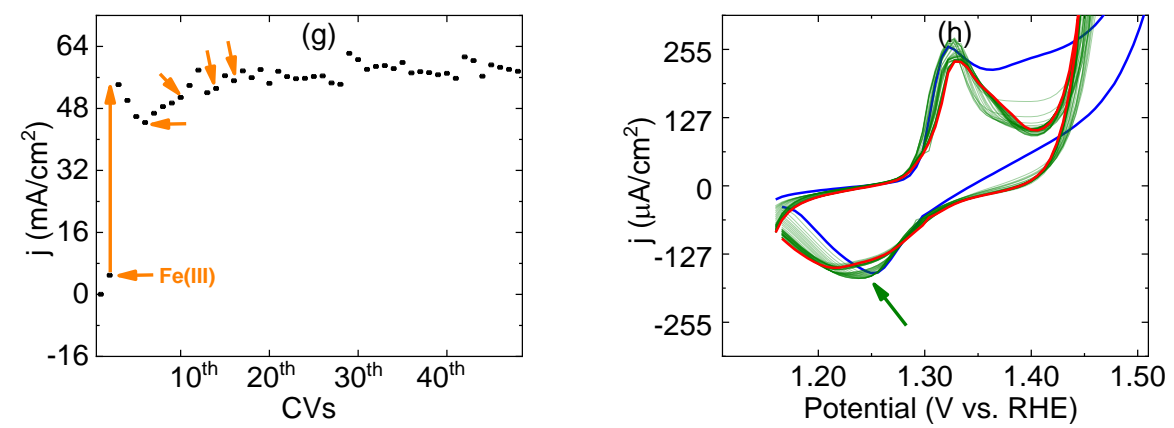

Figure S11 Chronoamperometry at $1.66 \mathrm{~V}$ in a $\mathrm{KOH}$ solution $(1.0 \mathrm{M})$ for a bare $\mathrm{GC}$ (blue) and the loaded precatalyst on the surface of a bare GC (red) (a). A decrease in the current density during chronoamperometry is related to catalyst detachment (a). After $250 \mathrm{~s}, \mathrm{Fe}(\mathrm{III})$ was added to the electrodes (a). CV (b,c) and LSV (d,e) before (blue), and after (red) attaching the precatalyst on the surface of GC after chronoamperometry in the presence of Fe(III) $(18 \mu \mathrm{M})$. Consecutive CVs of the precatalyst loaded on the surface of a bare GC (f-h). The current density at $1.66 \mathrm{~V}$ for the consecutive CVs in the image $f(g)$. Orange arrows show the time of addition of the Fe(III). CV and LSV were recorded in a KOH solution (1.0 $\mathrm{M})$ at a scan rate of $10.0 \mathrm{mV} / \mathrm{s}$. The blue arrows show the oxidation peaks for $\mathrm{NiO} / \mathrm{NiOOH}$. Green arrows indicate the reduction peaks for $\mathrm{NiOOH} / \mathrm{NiO}$. 


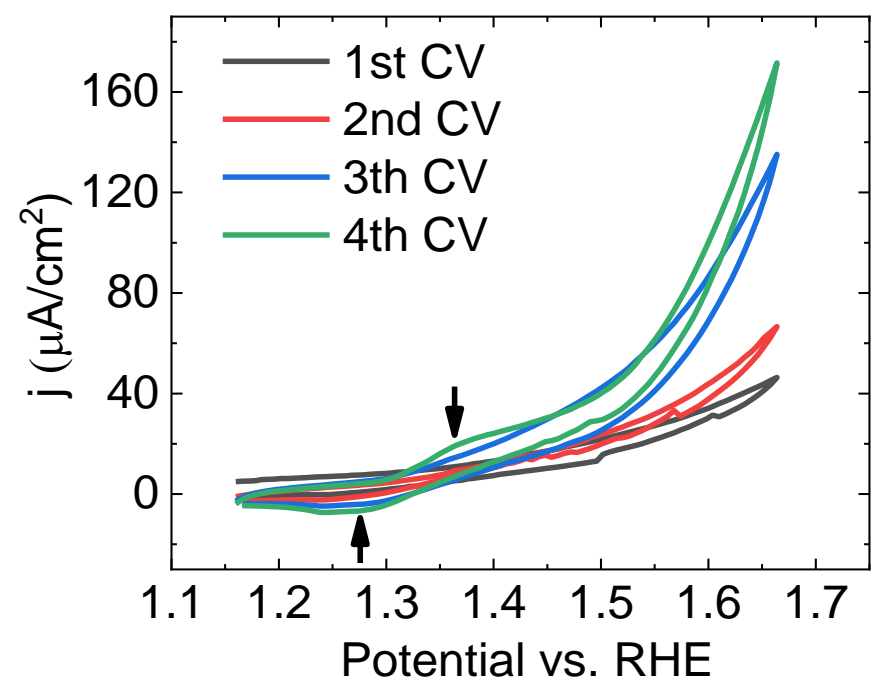

Figure S12 Four consecutive CVs in a $\mathrm{KOH}$ solution $(1.0 \mathrm{M})$ for the loaded precatalyst on the surface of a bare GC in the absence of Fe(III). The black arrows show the related peak for $\mathrm{Ni}$ in $\mathrm{Ni}$ oxide. 

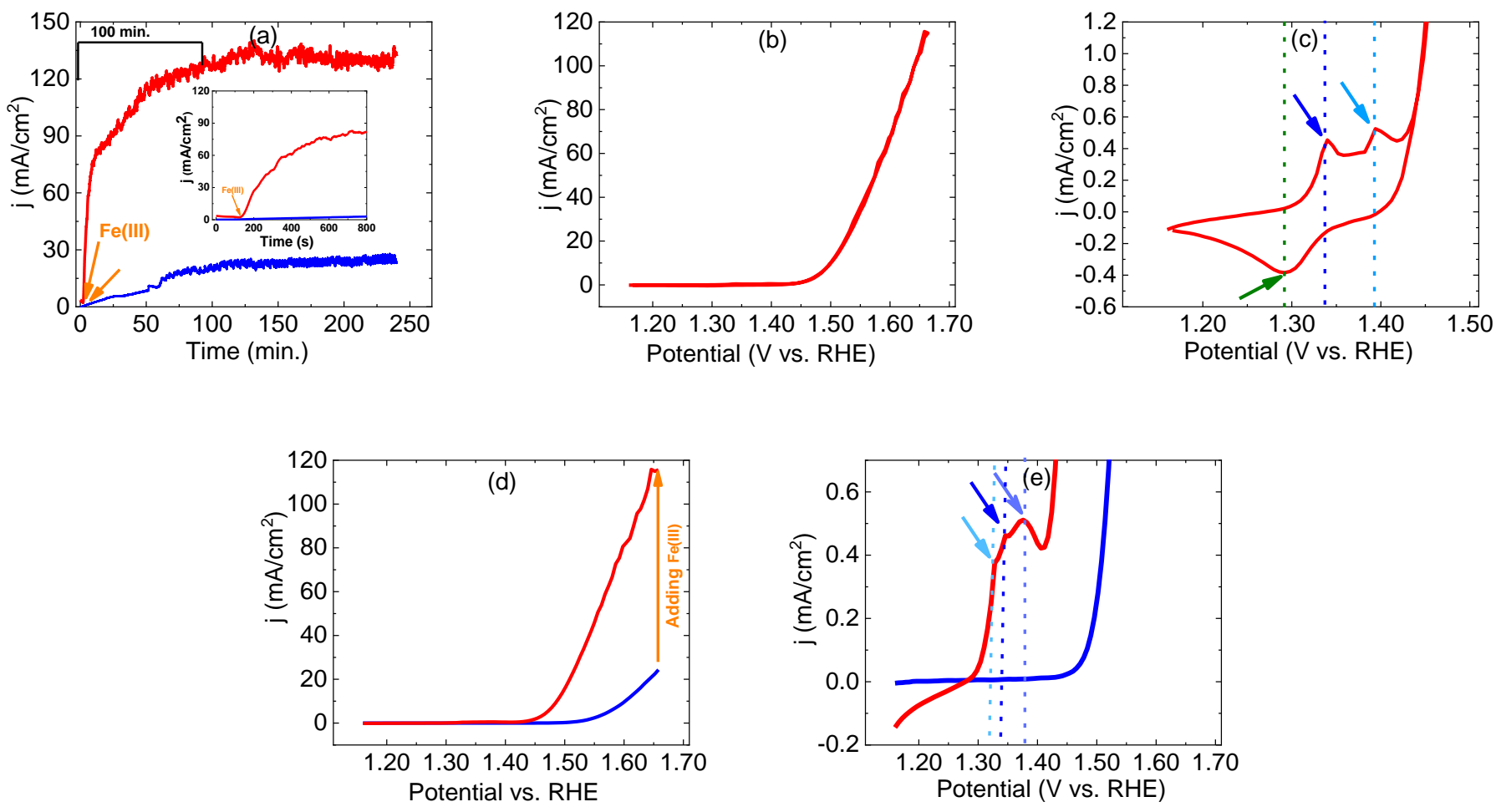

Figure S13 Chronoamperometry at $1.66 \mathrm{~V}$ in a $\mathrm{KOH}$ solution (1.0 M) of an Au electrode (blue) and the precatalyst loaded on the surface of an Au electrode (red) (a). After $120 \mathrm{~s}, \mathrm{Fe}(\mathrm{III})(18 \mu \mathrm{M})$ was added to the electrodes (a). CV (b,c) and LSV (d,e) before (blue) and after (red) of the attaching the precatalyst on the surface of an Au electrode after chronoamperometry. CV and LSV were recorded in a $\mathrm{KOH}$ solution $(1.0 \mathrm{M})$ at a scan rate of $10.0 \mathrm{mV} / \mathrm{s}$. The blue arrows show the oxidation peak for $\mathrm{NiO} / \mathrm{NiOOH}$. The green arrow shows the reduction. 

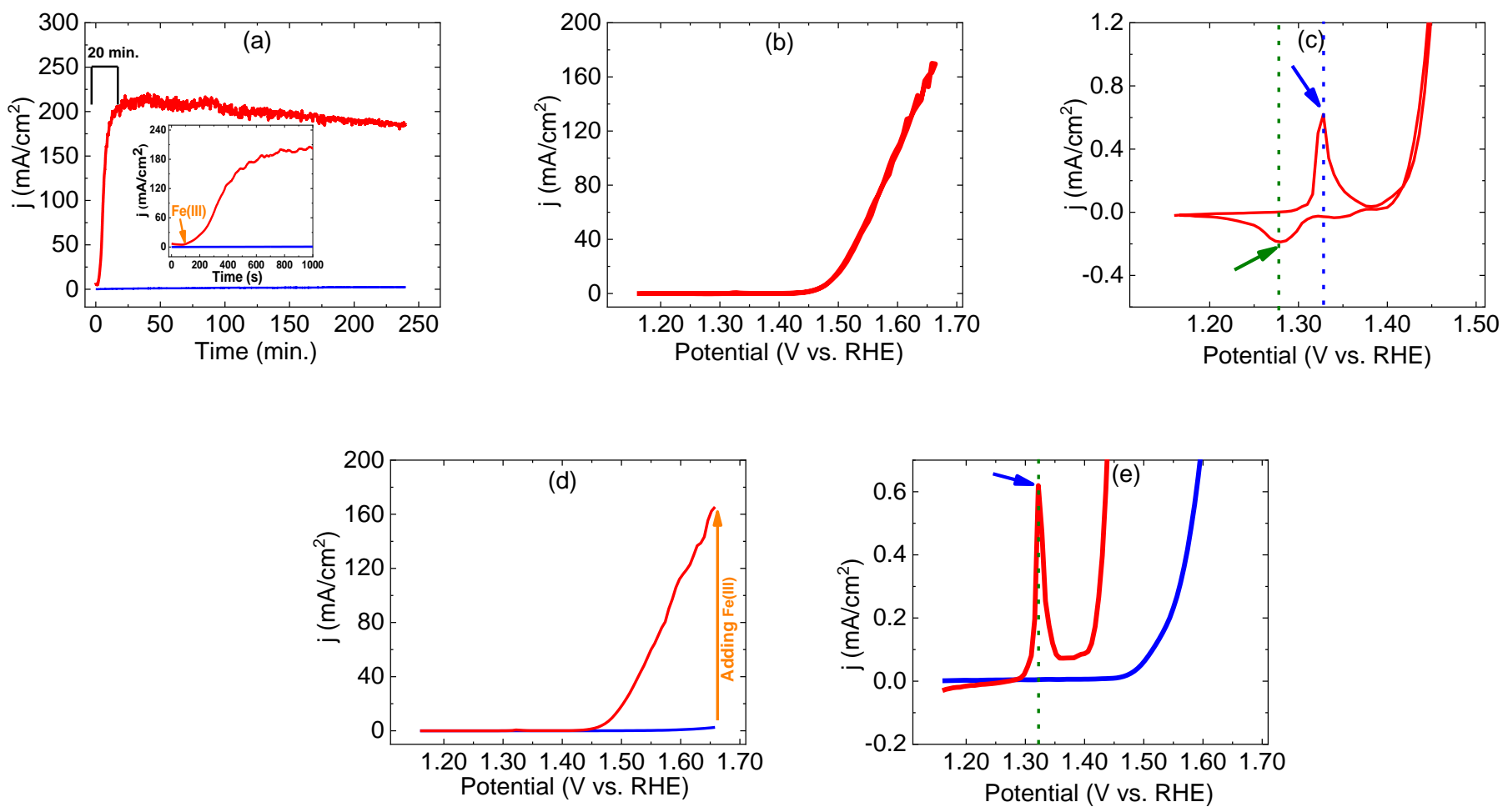

Figure S14 Chronoamperometry at $1.66 \mathrm{~V}$ in a $\mathrm{KOH}$ solution $(1.0 \mathrm{M})$ of a Pt electrode (blue) and the precatalyst loaded on the surface of a Pt electrode (red) (a). After $100 \mathrm{~s}, \mathrm{Fe}(\mathrm{III})(18 \mu \mathrm{M})$ was added to the electrolyte (a). CV $(b, c)$ and LSV $(d, e)$ of the precatalyst loaded on the surface of a Pt electrode before (blue) and after adding the Fe(III) and chronoamperometry (red). CV and LSV were recorded in a $\mathrm{KOH}$ solution $(1.0 \mathrm{M})$ at a scan rate of $10.0 \mathrm{mV} / \mathrm{s}$. The blue arrows show the oxidation peak for $\mathrm{NiO} / \mathrm{NiOOH}$. The green arrow shows the reduction peak for $\mathrm{NiOOH} / \mathrm{NiO}$. 

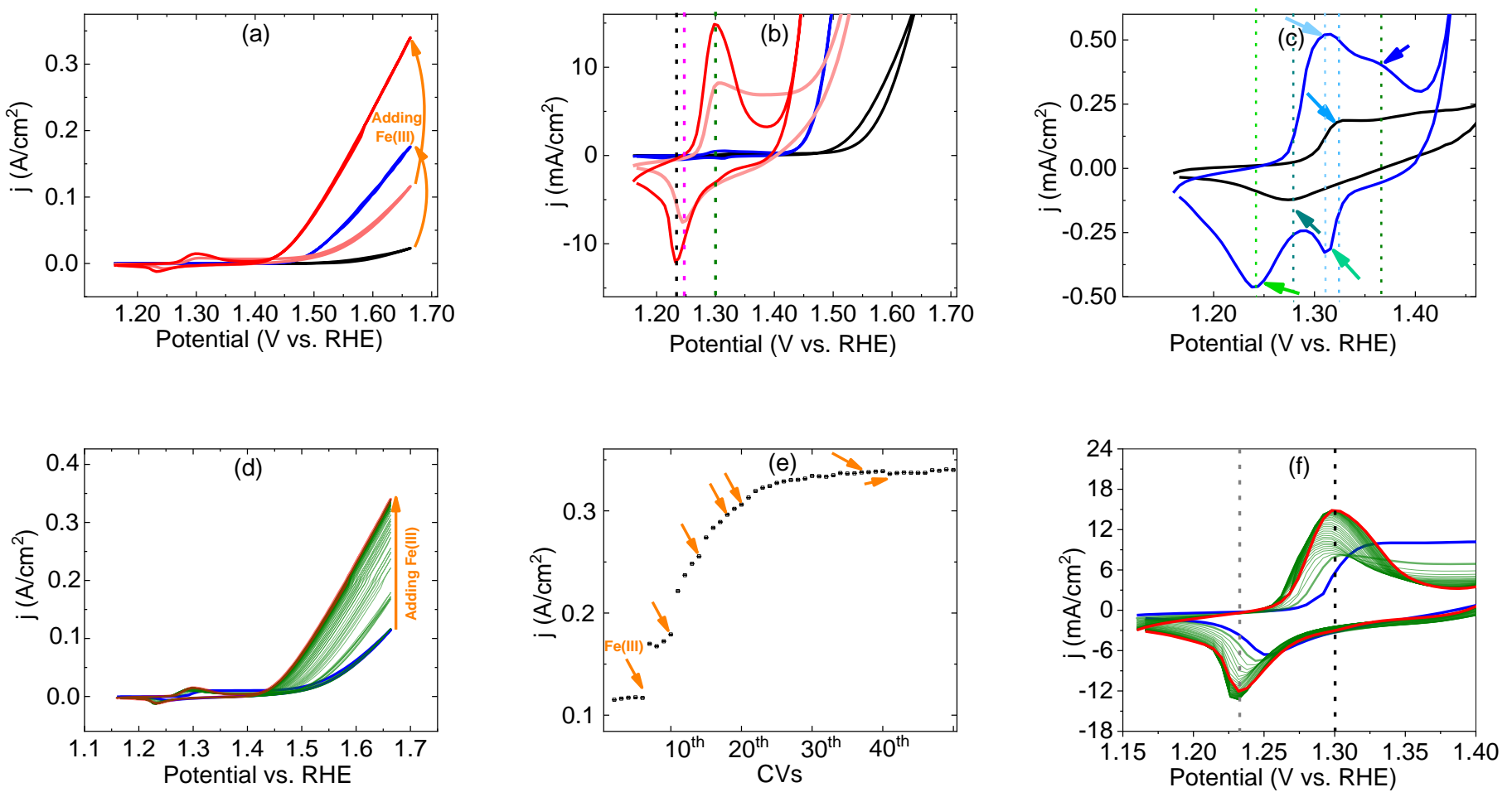

Figure S15 CVs for the precatalyst loaded on the surface of a bare Ni foam before (light red) and after adding the Fe(III) (red) (a,b). CVs for a bare Ni foam covered by Nafion before (black) and after adding the $\mathrm{Fe}$ (III) (blue) (a-c). The blue arrows show the oxidation peak for $\mathrm{NiO} / \mathrm{NiOOH}$. The green arrows show the reduction peak for $\mathrm{NiOOH} / \mathrm{NiO}$ (c). Consecutive $\mathrm{CVs}$ of the precatalyst loaded on the surface of a bare $\mathrm{Ni}$ foam (d-f). The current density at $1.66 \mathrm{~V}$ for the consecutive CVs in the image $d(e)$. The orange arrows show the addition of the $\mathrm{Fe}(\mathrm{III})$. CVs were recorded in a $\mathrm{KOH}$ solution $(1.0 \mathrm{M})$ at a scan rate of $10.0 \mathrm{mV} / \mathrm{s}$. 
Table S1 Comparison of some heterogeneous water-oxidizing catalysts.

\begin{tabular}{|c|c|c|c|c|}
\hline Compound & $\eta^{[a]}(m V)$ & $\eta^{[b]}(m V)$ & $\mathrm{pH}$ & Ref. ${ }^{[d]}$ \\
\hline $\mathrm{NiO}_{x} / \mathrm{Fe}$ & 217 & $\sim 287$ & 13 & This work \\
\hline $\mathrm{NiFeO}_{x}$ & - & 297 & 14 & 2 \\
\hline $\mathrm{NiO}_{x}$ & $>400$ & $>1000$ & 14 & 3 \\
\hline $\mathrm{NiO}_{x}$ & - & 300 & 14 & 2 \\
\hline $\mathrm{CoO}_{x}$ & - & 381 & 14 & 2 \\
\hline $\mathrm{NiCoO}_{x}$ & - & 312 & 14 & 2 \\
\hline $\mathrm{FeO}_{\mathrm{x}}$ & 345 & 445 & 14 & 4 \\
\hline $\mathrm{FeO}_{x}$ & - & 405 & 14 & 2 \\
\hline $\mathrm{Fe}_{2} \mathrm{O}_{3}$ & $<350$ & 430 & 14 & 5 \\
\hline $\mathrm{MnO}_{\mathrm{x}}$ & 320 & 514 & 14 & 2 \\
\hline $\mathrm{Fe}_{3} \mathrm{Ni}_{2} \mathrm{O}_{x}$ & 270 & - & 13 & 6 \\
\hline $\mathrm{FeNiO}_{x}$ & 211 & - & 13 & 7 \\
\hline $\mathrm{Fe}_{2} \mathrm{Ni}_{3} \mathrm{O}_{\mathrm{x}}$ & 190 & 250 & 13 & 8 \\
\hline $\mathrm{NiO}_{x}$ & 191 & 280 & 13 & 7 \\
\hline $\mathrm{NiO}_{x}$ & 295 & - & 13 & 9 \\
\hline $\mathrm{CoFeO}_{x}^{[c]}$ & 397 & - & 13 & 10 \\
\hline $\mathrm{CoO}_{x}$ & $<200$ & $<250$ & 13 & 11 \\
\hline $\mathrm{FeO}_{x}$ & 320 & 410 & 13 & 7 \\
\hline $\mathrm{CoO}_{\mathrm{x}}$ & 210 & 270 & 13 & 7 \\
\hline $\mathrm{CoO}_{x}$ & 295 & - & 13 & 6 \\
\hline $\mathrm{FeCoO}_{x}$ & 181 & - & 13 & 7 \\
\hline $\mathrm{FeCoNiO}_{x}$ & 191 & - & 13 & 7 \\
\hline $\mathrm{Ni}_{2} \mathrm{FeAlO}_{x}$ & 270 & - & 13 & 6 \\
\hline $\mathrm{NiFeMo}_{3} \mathrm{O}_{x}$ & 250 & - & 13 & 6 \\
\hline $\mathrm{Ni}_{2} \mathrm{FeCr}_{2} \mathrm{O}_{x}$ & 240 & - & 13 & 6 \\
\hline $\mathrm{NiFeGa}_{3} \mathrm{O}_{x}$ & 240 & - & 13 & 6 \\
\hline $\mathrm{CoSe}_{2}$ & 373 & 380 & 13 & 12 \\
\hline $\mathrm{NG}-\mathrm{CoSe}_{2}$ & 294 & 320 & 13 & 12 \\
\hline $\mathrm{MnO}_{\mathrm{x}}$ & $<300$ & $>1000$ & $>11.5$ & 13 \\
\hline $\mathrm{FeOOH}$ & 300 & 420 & 11 & 14 \\
\hline $\mathrm{NiB}_{\mathrm{i}}$ & 300 & 425 & 9.2 & 15 \\
\hline $\mathrm{MnO}_{\mathrm{x}}$ & $<300$ & $>1000$ & $8.5-5.5$ & 13 \\
\hline $\mathrm{CoO}_{x}$ & $<200$ & $<300$ & 7 & 11 \\
\hline $\mathrm{MnO}_{\mathrm{x}}$ & 390 & 590 & 7 & 16 \\
\hline $\mathrm{MnO}_{\mathrm{x}}$ & 441 & 600 & 7 & 17 \\
\hline CoFePBA & 291 & $>600$ & 7 & 18 \\
\hline $\mathrm{MnO}_{\mathrm{x}}$ & 150 & $>1000$ & 7 & 19 \\
\hline $\mathrm{CoP}_{i}$ & 281 & 410 & 7 & 20 \\
\hline $\mathrm{MnO}_{\mathrm{x}}$ & $>700$ & $>1000$ & 7 & 21 \\
\hline $\mathrm{Li}_{x} \mathrm{MnP}_{2} \mathrm{O}_{7}$ & 500 & - & 7 & 22 \\
\hline $\mathrm{MnO}_{\mathrm{x}}$ & $<300$ & $>1000$ & 3.5 & 13 \\
\hline $\mathrm{Co}^{2+}(1 \mathrm{M})$ & $<580$ & 600 & 1 & 11 \\
\hline
\end{tabular}

[a] Onset overpotentiol.

[b] @1 m/Acm².

[c] LDH.

[d] For an excellent review see ref. 23 


\section{References}

1. Xiao X.; Bard A. J. Observing single nanoparticle collisions at an ultra-microelectrode by electrocatalytic amplification. J. Am. Chem. Soc., 2007, 129, 9610-9612.

2. Trotochaud, L.; Ranney, J. K.; Williams, K. N.; Boettcher, S. W., Solution-cast metal oxide thin film electrocatalysts for oxygen evolution. J. Am. Chem. Soc., 2012, 134 (41), 17253-17261.

3. Trotochaud, L.; Young, S. L.; Ranney, J. K.; Boettcher, S. W., Nickel-iron oxyhydroxide oxygenevolution electrocatalysts: the role of intentional and incidental iron incorporation. J. Am. Chem. Soc., 2014, 136 (18), 6744-6753.

4. Doyle, R.; Lyons, M., Kinetics and mechanistic aspects of the oxygen evolution reaction at hydrous iron oxide films in base. J. Electrochem. Soc., 2013, 160 (2), H142-H154.

5. $\quad$ Qiu, Y.; Leung, S.-F.; Zhang, Q.; Hua, B.; Lin, Q.; Wei, Z.; Tsui, K.-H.; Zhang, Y.; Yang, S.; Fan, Z., Efficient photoelectrochemical water splitting with ultrathin films of hematite on three-dimensional nanophotonic structures. Nano lett., 2014, 14 (4), 2123-2129.

6. Chen, J. Y.; Miller, J. T.; Gerken, J. B.; Stahl, S. S., Inverse spinel $\mathrm{NiFeAlO}_{4}$ as a highly active oxygen evolution electrocatalyst: promotion of activity by a redox-inert metal ion. Energy Environ. Sci., 2014, 7 (4), 1382-1386.

7. Smith, R. D.; Prévot, M. S.; Fagan, R. D.; Zhang, Z.; Sedach, P. A.; Siu, M. K. J.; Trudel, S.; Berlinguette, C. P., Photochemical route for accessing amorphous metal oxide materials for water oxidation catalysis. Science, 2013, 1233638.

8. Smith, R. D.; Prévot, M. S.; Fagan, R. D.; Trudel, S.; Berlinguette, C. P., Water oxidation catalysis: electrocatalytic response to metal stoichiometry in amorphous metal oxide films containing iron, cobalt, and nickel. J. Am. Chem. Soc., 2013, 135 (31), 11580-11586.

9. Shaidarova, L.; Davletshina, L.; Budnikov, G., Flow-injection determination of water-soluble vitamins B 1, B 2, and B 6 from the electrocatalytic response of a graphite electrode modified with a ruthenium (III) hexacyanoruthenate (II) film. J. Anal. Chem., 2006, 61 (5), 502-509.

10. Abellán, G.; Carrasco, J. A.; Coronado, E.; Romero, J.; Varela, M., Alkoxide-intercalated CoFelayered double hydroxides as precursors of colloidal nanosheet suspensions: structural, magnetic and electrochemical properties. J. Mater. Chem. C, 2014, 2 (19), 3723-3731.

11. Gerken, J. B.; McAlpin, J. G.; Chen, J. Y.; Rigsby, M. L.; Casey, W. H.; Britt, R. D.; Stahl, S. S., Electrochemical water oxidation with cobalt-based electrocatalysts from $\mathrm{pH} 0-14$ : the thermodynamic basis for catalyst structure, stability, and activity. J. Am. Chem. Soc., 2011, 133 (36), 14431-14442.

12. Gao, M.-R.; Cao, X.; Gao, Q.; Xu, Y.-F.; Zheng, Y.-R.; Jiang, J.; Yu, S.-H., Nitrogen-doped graphene supported $\mathrm{CoSe}_{2}$ nanobelt composite catalyst for efficient water oxidation. ACS Nano 2014, 8 (4), 39703978.

13. Huynh, M.; Bediako, D. K.; Nocera, D. G., A functionally stable manganese oxide oxygen evolution catalyst in acid. J. Am. Chem. Soc., 2014, 136 (16), 6002-6010.

14. Chemelewski, W. D.; Lee, H.-C.; Lin, J.-F.; Bard, A. J.; Mullins, C. B., Amorphous FeOOH oxygen evolution reaction catalyst for photoelectrochemical water splitting. J. Am. Chem. Soc., 2014, 136 (7), 2843-2850.

15. Dincă, M.; Surendranath, Y.; Nocera, D. G., Nickel-borate oxygen-evolving catalyst that functions under benign conditions. Proc. Natl. Acad. Sci., 2010, 107 (23), 10337-10341.

16. Zaharieva, I.; Chernev, P.; Risch, M.; Klingan, K.; Kohlhoff, M.; Fischer, A.; Dau, H., Electrosynthesis, functional, and structural characterization of a water-oxidizing manganese oxide. Energy Environ. Sci., 2012, 5 (5), 7081-7089.

17. Indra, A.; Menezes, P. W.; Zaharieva, I.; Baktash, E.; Pfrommer, J.; Schwarze, M.; Dau, H.; Driess, M., Active Mixed-Valent $\mathrm{MnO}_{x}$ Water Oxidation Catalysts through Partial Oxidation (Corrosion) of Nanostructured MnO Particles. Angew. Chem. Int. Ed., 2013, 52 (50), 13206-13210. 
18. Pintado, S.; Goberna-Ferrón, S.; Escudero-Adán, E. C.; Galán-Mascarós, J. R. n., Fast and persistent electrocatalytic water oxidation by Co-Fe Prussian blue coordination polymers. J. Am. Chem. Soc., 2013, 135 (36), 13270-13273.

19. Singh, A.; Hocking, R. K.; Chang, S. L.-Y.; George, B. M.; Fehr, M.; Lips, K.; Schnegg, A.; Spiccia, L., Water oxidation catalysis by nanoparticulate manganese oxide thin films: probing the effect of the manganese precursors. Chem. Mater., 2013, 25 (7), 1098-1108.

20. Kanan, M. W.; Nocera, D. G., In situ formation of an oxygen-evolving catalyst in neutral water containing phosphate and $\mathrm{Co}^{2+}$. Science, 2008, 321 (5892), 1072-1075.

21. Bergmann, A.; Zaharieva, I.; Dau, H.; Strasser, P., Electrochemical water splitting by layered and 3D cross-linked manganese oxides: correlating structural motifs and catalytic activity. Energy Environ. Sci., 2013, 6 (9), 2745-2755.

22. Park, J.; Kim, H.; Jin, K.; Lee, B. J.; Park, Y.-S.; Kim, H.; Park, I.; Yang, K. D.; Jeong, H.-Y.; Kim, J., A new water oxidation catalyst: lithium manganese pyrophosphate with tunable Mn valency. J. Am. Chem. Soc., 2014, 136 (11), 4201-4211.

23 Galan-Mascarós, J. R., Water oxidation at electrodes modified with earth-abundant transition-metal catalysts. ChemElectroChem, 2015, 2 (1), 37-50. 